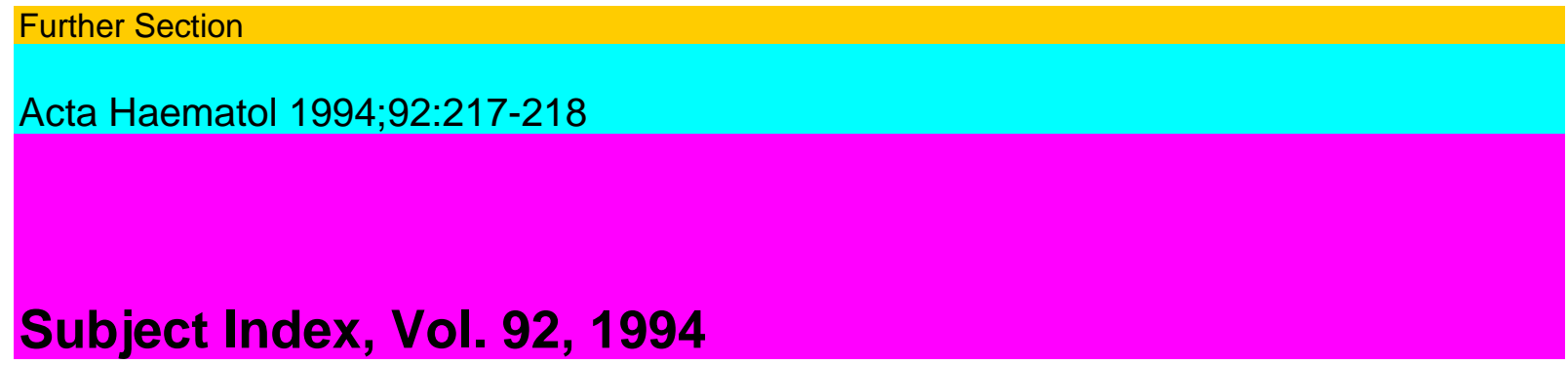

Vol 92, Supplement 1, has its own Subject

Acute and chronic phases 104

leukemia 14,150

lymphoblastic leukemia 208

myeloid leukemia 18,123

promyelocytic leukemia 109 AIDS 197

Alglucerase 187

Allele-specific oligonucleotide hybridization 176

Allogeneic bone marrow transplantation 169

Allosteric kinetics 91

An(a)emia 29, 160

-, chronic disorders 126

Antisense oligodeoxynucleotides 190

Antithymocyte globulin 136

Arsenic intoxication 142

Autoimmune hemolytic anemia 42

Autoimmunity 136

Azidothymidine 182

Basophilia 109 BCR-ABL 97, 190 BCR-ABL-mRNA 169 BFU-E 182 Bone marrow 182

- $\quad$ tumor 148

Buserelin acetate 42

Cancer diathesis 150 CD21 8 CD33 23 CD34 23

Cell surface phenotype 157 CFU-E 182 CFU-GM $182 \gamma$-Chain ratio 79 Childhood 36

Cholesterol 61

Chromosomal instability syndromes 150 Chronic my elogenous leukemia 101, 169, 190

myeloid leukemia 97

my elomonocytic leukemia 104 Consanguinity 208 Cyclosporine 136 Cytochemistry 113

Cytogenetics 169

Cytokines 130 Cytomegalovirus 39 Cytosine arabinoside 14

Down's syndrome pregnancy 113

Enzyme 91

Epipodophyllotoxin 33 Epstein-Barr virus 8 Erythrocyte 91 Erythropoietin 79, 182 Ethnicity 18

Extradural tumor 148

Familial leukemia 208 Felty's syndrome 154 Fetal hemoglobin 79 Flow cytometry 23, 197

Gaucher disease 187

Gonadotropin-releasing hormone analogue 42

Granulocyte-macrophage colony-stimulating factor 154 
H(a)emolytic an(a)emia 39, 91 Hairy cell leukaemia 8 HbH disease 176 Hematopoiesis 197 Hemoglobinopathies 176 Hemopoietic progenitors 42 Histamine 109 HLA antibody 57 HLA-DR 23

Hodgkin's disease 97,148 Human monocytes 66

ICSH 91

IgD myeloma 144

Immune hyperthyroidism 136

Immunochemistry 113

Immunofixation 144

Immunoglobulin isotype production 71

Immunosuppression 136

Interleukin-4 104

Interleukin-6 1, 8

Iron 66

- overload 126

k light chain 144

Large granular lymphocytosis 157 Leukopenia 61,154 Lineage involvement 88 Liver 187

Lysosomes 66

Macrocytosis 142

Magnetic resonance imaging 187

217

MAIDS 182

Malignancy 150

Maturation arrest 29

Megaloblastic anaemia 126

Mitoxantrone 14

Monoclonal gammopathy of undetermined

significance 1 Monosomy 736 Morphology antibody chromosomes

method 88 Multiple cranial neuritis 157

myeloma 1,71

sclerosis 136

transfusions 57 Myelodysplasia 36 Myelodysplastic syndrome(s) 33, 150 Myelofibrosis 160

Myeloma 126 Myelosuppression 130

Neuropathy 142

Neutropenia 61,154

Neutrophil alkaline phosphatase 113

Oncogene 101

PCR, haplotypes 83

Peripheral blood stem cell transplantation

23 Ph1 chromosome 97 Phagosomes 66 Phenytoin 204 Plasma cell 126 Platelet antibody 57

Polymerase chain reaction 97,190 Positive direct antiglobulin test 39 Premature aging 150 PSK

130

Pure red cell aplasia 29, 42 Pyruvate kinase 91

- $\quad$ - variant 91

RAEB-t 150

RAS mutations 123 


\section{Rat 61}

Red cell antibody 57

Renal cell carcinoma 119

Residual leukemic cells 169

Retinoicacid 109

RT-PCR 169

Secondary leukemia 101 Serum markers 1

protein electrophoresis 144 Severe aplastic anemia 136

combined immunodeficiency 160 Sézary syndrome 204

Sickle cell anemia 119,176

- $\quad$ cell//3-thalassemia 79

Southern blot 83

$\mathrm{t}(9 ; 11)(\mathrm{p} 22 ; \mathrm{q} 23) 33$

$\mathrm{T}$ cell receptor gene rearrangement 157

Thalassemia 66, 176

$\delta \beta$-Thalassemia 83

Therapy-related leukemia 33

Thrombocytopenia 160

Thyroiditis 136

Transient erythroblastopenia, childhood 29

Translocations: 8;21 and 15; 1788

Tumor suppressor gene 101

Ultrasound 187

Vitamin D deficiency 160

Werner's syndrome 150

Subject Index 